\title{
O uso da internet por adolescentes e as transformações nas relações de poder da família contemporânea
}

The use of the internet by adolescents and the transformations in the power relationships of the contemporary family

Sara Helen dos Santos de Souza ${ }^{1}$ e Ivana Maria Schnitman ${ }^{2}$

1 Universidade Federal do Sul da Bahia, Bacharel em Humanidades, Graduanda de Psicologia, Brasil, E-mail: sarahelensouza@gmail.com, ORCID: https://orcid.org/0000-0003-2780-3818

2 Universidade Federal do Sul da Bahia, Centro de Formação em Ciências Humanas e Sociais, Brasil, E-mail: ivanaufsb@gmail.com, ORCID: https://orcid.org/0000-0001$\underline{5932-8797}$

ARTICLE INFO

Article history:

Received 2020-12-17

Accepted 2021-05-04

Available online 2021-05-04
Palavras-chave: Relações familiares. Adolescência. Contemporaneidade. Internet.

Keywords: Family relationships. Adolescence. Contemporaneity. Internet.

RESUMO. A instituição familiar vem passando por transformações impulsionadas pelo contexto sociocultural da pós-modernidade, alterando assim as relações de poder existentes. Com a disseminação da internet no cotidiano da vida de pais e filhos, o comportamento do adolescente contemporâneo ganha novos contornos, o que influencia e indica mudanças das relações de poder na família. Assim, o presente estudo buscou, compreender as relações de poder entre pais e filhos na sociedade contemporânea através da análise do uso da internet por adolescentes. Para fins desta pesquisa, três famílias com filhos adolescentes, entre 11 e 15 anos e que possuem acesso à internet, foram entrevistadas e observadas. Através da análise dos dados, pôde-se perceber que aspectos pós-modernos e tradicionais coexistem, caracterizando as relações familiares de poder como híbridas.

ABSTRACT. The family institution has been undergoing transformations driven by the socio-cultural context of postmodernity, thus altering the existing power relations. With the spread of the internet in the daily lives of parents and children, the behavior of contemporary adolescents gains new contours, which influences and indicates changes in the power relationships in the family. Thus, the present study sought to understand the power relations between parents and children in contemporary society through the analysis of adolescents' use of the internet. For the purposes of this research, three families with adolescent children, between 11 and 15 years old and who have access to the internet, were interviewed and observed. Through the analysis of the data, it was possible to perceive that postmodern and traditional aspects coexist, characterizing family power relations as hybrids. 


\section{Introdução}

A família é uma instituição antiquíssima e de extrema importância em toda a história humana, sendo, na maioria das vezes, a responsável pelo primeiro contato do indivíduo com o mundo. A "socialização primária" tem um papel primordial na construção da subjetividade, sendo através dos laços familiares, a forma que o indivíduo vai se situando, espacial e temporalmente, e assumindo sua identidade na sociedade a qual pertence (BERGER e LUCKMANN, 2004).

No entanto, apesar de ser uma instituição presente em grande parte da história da humanidade, a família não manteve uma estrutura fixa ao longo dos séculos. Sendo influenciada por fatores históricos, culturais, sociais e ambientais, esta adquiriu os mais diversos contornos, sempre no intuito de se adaptar, sendo, em grande parte, fruto do seu meio e refletindo as crenças de sua época e as condições específicas de vida dos seus integrantes (PRATTA e SANTOS, 2007), razão, pela qual, apesar de se perceber a exaltação de modelos específicos de família em determinados momentos da história, é preciso considerar que esses não foram os únicos modelos existentes.

$\mathrm{Na}$ sociedade contemporânea, a família passa por intensas transformações, modificando sua composição e suas relações internas de poder, o que afeta, diferentemente, cada um de seus membros. Diante disso, a adolescência, no contexto pós-moderno, ganha contornos peculiares ao ser influenciada por essas relações através da convivência com seus pais no ambiente doméstico. A adolescência é reconhecida não só como uma fase biológica, implicando em uma série de mudanças físicas e emocionais, mas também pela busca da consolidação de uma identidade, estando a adolescência também, influenciada pela época na qual está inserida (SALLES, 2005).

Nascidos na era digital, vários dos adolescentes na contemporaneidade têm as tecnologias digitais altamente disseminadas em sua vida cotidiana. Estima-se, segundo dados da pesquisa Tic Kids Online Brasil, feita pela Cetic.br (Centro Regional de Estudos para o Desenvolvimento da Sociedade da Informação, 2016) que em 2016, $80 \%$ das crianças e adolescentes brasileiros, de 9 a 17 anos de idade, eram usuárias da Internet.

Sabe-se que no contexto contemporâneo, a internet é um poderosíssimo agente de mudanças. Mas, justamente por estar tão disseminada na vida de alguns adolescentes e suas famílias, ela assume um status não só de influenciadora, mas também de indicadora de mudanças. Assim, transforma-se em uma forma de expressão não só de um dos muitos modos de vida do adolescente contemporâneo, mas também das relações de poder entre esse adolescente e seus pais.

Nesse sentido, analisar o uso da tecnologia e da internet nas relações entre pais e filhos adolescentes pode ser de grande valia, não só para perceber como o uso de tecnologias digitais se expressa nas relações de poder, mas também para entender melhor as próprias relações de poder entre pais/mães e filhos/as adolescentes na contemporaneidade e suas possíveis implicações, uma vez que o tecido social é constituído por indivíduos e parte importante da personalidade e individualidade é formada na adolescência e no seio familiar.

Nessa perspectiva, o presente trabalho tem como objetivo compreender as relações de poder entre pais/mães e filhos/as adolescentes na sociedade contemporânea, a partir da análise do uso da internet. Para tal, buscou-se apontar os usos da internet por adolescentes, identificar estratégias de controle e de fuga de 
controle por parte de pais e filhos no que diz respeito ao uso da internet e refletir acerca das relações de poder entre pais/mães e filhos/as expressas no uso da internet.

\section{A Família na Contemporaneidade}

A definição prática de família é dada por Giddens e Sutton (2017, p.193) como: "Grupo de indivíduos ligado por laços consanguíneos, casamento ou adoção, que formam uma unidade socioeconômica, sendo os membros adultos os responsáveis pela criação dos filhos", esse grupo pode ter diversas configurações. Durante grande parte do século $X X$, o modelo dominante de família era tradicional, fortemente patriarcal, onde o homem era o chefe da família e as relações entre pais e filhos eram assimétricas e baseadas na autoridade. A partir da década de sessenta, sob o forte impacto causado na sociedade pela ocorrência de duas guerras mundiais e 0 surgimento das tecnologias digitais, a estrutura familiar passa se modificar (BARRETO, 2015).

$\mathrm{Na}$ década de 60 a mulher começa a adentrar o mercado de trabalho, o que permite que ela ocupe outros lugares além do de dona de casa e cuidadora dos filhos e atenua parte da desigualdade econômica existente ente ela e o homem, antes único detentor do poder econômico. O surgimento da pílula anticoncepcional, que traz para a mulher mais liberdade para escolher quando e quantos filhos quer ter, amplia suas possibilidades de ascensão ao mercado de trabalho (HINTZ, 2001).

Empregada, a mulher não adquire apenas a chance de contribuir financeiramente com o sustento da casa, mas, na medida em que se vê financeiramente independente de seu marido, acaba por fomentar uma relação mais igualitária entre estes (JUTKOSKI, 2009). Sobre esta questão, Petrini (2005 apud JUTKOSKI, 2009, p. 42), diz que:

O valor da igualdade foi aos poucos sendo incorporado ao quotidiano da convivência familiar, o que acabou ocasionando formas mais democráticas e igualitárias de partilhar tarefas entre marido e mulher. Os modelos tradicionais são abandonados, onde atribuíam o primado ao marido, e às mulheres somente as tarefas domésticas. Estas novas configurações surgem com o fato de existir uma independência econômica dos cônjuges, o que configura uma responsabilidade familiar mais compartilhada e posição social igualitária.

Dessa forma, os papéis de gênero pré-estabelecidos, homem provedor e mulher responsável pela criação dos filhos, se enfraquecem, abalando fortemente a estrutura de poder da família patriarcal, alicerçada na diferença entre papéis femininos e masculinos. (DUARTE, 2001) Como consequência desse fato, as relações entre marido e mulher passam a se pautar mais no afeto e realização pessoal (HINTZ, 2001), afirmando a individualidade frente aos papéis socialmente estabelecidos (JUTKOSKI, 2009).

A modificação nas relações entre marido e mulher acaba por repercutir nas relações entre pais e filhos (JUTKOSKI, 2009), que posteriormente, devido à valorização da individualidade e a consequente contestação da hierarquia familiar, passam a ser alvo de negociações (JUTKOSKI, 2009; HINTZ, 2001; OLIVEIRA, 2010). Percebe-se, assim, que a família é fortemente afetada pelas mudanças ocorridas na sociedade, havendo inclusive influências que vão do público para o privado. De acordo com Duarte (2001, p. 11), "Poderíamos dizer que a família reproduz, no espaço 
privado, o mesmo processo de modernização da sociedade brasileira. Reveste-se de ideais igualitários, libera costumes até então reprimidos e altera personagens no poder".

$\mathrm{Na}$ contemporaneidade, esse fluxo de mudanças do público para o privado continua, e a família se vê fortemente influenciada pela crescente ruptura dos paradigmas e modelos que até então eram vigentes. Para Vaitsman (1994, p.19), a família pós-moderna pode ser definida pela "inexistência de um modelo dominante, seja no que diz respeito às práticas, seja enquanto um discurso normatizador das práticas". Dessa forma, a multiplicidade de modelos familiares atuais, decorrentes das várias formas de se relacionar, e a mudança nas relações de poder dentro do ambiente familiar são aspectos que demonstram a configuração menos hierárquica e estrita da sociedade atual.

Para os fins desse trabalho, entende-se por "Modernidade" a época que se inicia no século XVIII, com o lluminismo europeu, até a recente década de 80 (GIDDENS e SUTTON, 2017, p. 22), e por "Pós-modernidade" a época sucessora que, segundo Giddens e Sutton (2017, p. 27), começa a se delinear nas esferas artística e cultural desde 1970, mas só impacta fortemente a teoria social na metade dos anos 1980.

A sociedade pós-moderna é de tal forma fragmentada e heterogênea que não há mais discursos legitimadores que possam abranger a totalidade das experiências vividas pelos indivíduos (VAITSMAN, 1995, p.21). Se, a modernidade podia ser caracterizada por uma definição clara de limites, hierarquias, papéis sociais e fronteiras, havendo rigidez de regras e definições, "a pós-modernidade é fluida, ou lisa, em virtude de sua descentralização, organização em redes, sua ausência de barreiras e fronteiras"(NICOLACl, 2004a, p.84). Enquanto a Modernidade é caracterizada pela "racionalização, democratização, individuação e ascensão da ciência" (GIDDENS e SUTTON, 2017, p.23), a Pós-modernidade tem como uma das suas características principais a perda da confiança na ciência, no progresso, na política, além do fluxo contínuo de informações que tornam possível o contato com as mais diversas ideias e valores (GIDDENS e SUTTON, 2017, p. 29-30). Segundo Giddens e Sutton (2017, p. 29) o mundo pós-moderno já não é mais ordenado por Estados nacionais e pode-se perceber isso através de diversos fenômenos:

"O rápido crescimento e disseminação da mídia de massa, novas tecnologias da informação, os movimentos mais fluidos de pessoas atravessando fronteiras nacionais, o fim das identidades de classe social e o surgimento de sociedade multiculturais [...].

As mudanças sociais, cada vez mais velozes, somadas à derrocada dos grandes discursos legitimadores e ao fluxo de informações contínuo desencadeiam falta de referenciais e valores norteadores de condutas, o que se reflete em diversos espaços da sociedade, entre os quais se inclui o familiar. Assim, a família se vê afetada por esses fenômenos de forma cada vez mais intensa, recebendo, consequentemente, influências do uso constante das novas tecnologias, portas de entrada para todo tipo de informação. Dentre estas, pode-se citar a Internet, capaz de fomentar novas formas de comunicação e identidades. (HINTZ, 2001; OLIVEIRA, 2010; PRATTA e SANTOS, 2007; TORRES e YACOUB, 2012).

Considerando que na contemporaneidade há uma menor rigidez dos modelos de conduta socialmente aceitos, ao flexibilizar suas relações de poder para se adaptar à época na qual está inserida, a família busca, de diferentes formas, manter-se e 
cumprir as suas funções essenciais, sendo estas: "promover o desenvolvimento contínuo dos pais, preservando a sua saúde física e mental e produzir filhos autônomos e saudáveis" (SOUZA, 1999, p.46).

\subsection{A adolescência, a família e a internet}

A adolescência, como é conhecida e representada hoje, nem sempre existiu. As mudanças físicas características da puberdade sempre estiveram presentes, mas a forma como essa fase da vida é vivenciada variou conforme o contexto cultural, social e a época em que o adolescente vivia. Torna-se importante evidenciar que adolescência e puberdade não são sinônimos (PRATTA e SANTOS, 2007). Sobre isso, Souza (1999, p. 14), ressalta que "a adolescência é um processo psicossocial que pode apresentar os primeiros sinais antes do início da pubescência e terminar depois da parada do crescimento físico". Dessa forma, enquanto a puberdade é universal, a adolescência é construída socialmente e está ligada a um retardamento da entrada do jovem na vida adulta (SOUZA, 1999).

Até meados da década de 60, os papéis sociais eram bem definidos, conforme o gênero e a faixa etária, sendo as relações de poder na família estabelecidas de forma rígida. Havia um maior controle dos pais sobre os filhos, sendo que estes se incumbiam de sua socialização, procurando moldar as crianças e adolescentes de acordo com o que consideravam correto (PRATTA e SANTOS, 2007).

A esse respeito, Salles diz (2005, p. 38):

A socialização, no sentido clássico, implica uma relação de desigualdade entre adulto e criança e um longo tempo de preparação no qual está embutida a ideia de que a criança com o ser em formação está inacabada. A socialização é sempre um processo que se dá do adulto sobre a criança.

Na sociedade moderna, vigorava a ideia de que as crianças e os adolescentes deviam ser devidamente instruídos e moldados para serem adultos (SALLES, 2005, p.36), pois somente adultos sabem conduzir suas vidas. As diferenças entre as várias fases da vida eram bem definidas (SALLES, 2005). De acordo com Salles (2005, p.37):

Na sociedade moderna a criança e o adolescente se socializam para se integrarem e de adaptarem à sociedade. Esse processo de socialização implica uma longa educação, com metas a longo prazo. Ao final do mesmo a criança deve chegar ao autocontrole, à autonomia e à independência que são características atribuídas ao adulto. A conduta de criança e de jovem devem ser superadas.

Em contrapartida, na sociedade contemporânea, observa-se que as relações entre adolescentes e seus pais tornaram-se mais flexíveis e horizontais, baseando-se mais na afeição e no diálogo, do que no exercício da autoridade e poder dos pais, característico da família tradicional (SALLES, 2005).

"Poder" tem sua definição prática dada por Giddens e Sutton (2017, p.330) como a "capacidade de indivíduos ou grupos de alcançar seus objetivos ou fazer valer seus interesses a despeito de oposições ou resistência". No modelo da família tradicional o poder dos pais é fortemente exercido sobre os filhos na medida em que são eles que decidem como o filho deverá se portar e impõe essa vontade à criança 
ou adolescente. No ideal de família contemporânea esse exercício do poder se altera, pois, os filhos passam a ser mais ouvidos.

Para Giddens (2007, p.71), é possível observar fortes semelhanças entre os princípios que norteiam o modelo ideal dos relacionamentos atuais, inclusive entre pais e filhos, e os princípios da democracia no âmbito político: ambos se baseiam em diálogo, confiança e ausência de coerção. Dessa forma, observa-se mais uma vez como a família absorve os valores em vigor na sociedade através da tendência para a flexibilização das relações, onde o poder dos pais não é mais exercido de forma tão autoritária como as típicas da família tradicional.

Ao mesmo tempo em que há uma flexibilização na forma como a autoridade é exercida, há também um conflito de valores que remete os pais a dúvida sobre como orientar os filhos, como torná-los adultos. Na socialização característica da sociedade moderna e da família tradicional, o adulto é o detentor do conhecimento e a criança ou adolescente aprende com ele como ser um adulto. Na sociedade contemporânea essa relação assimétrica se enfraquece diante das incertezas dos pais sobre quais valores e condutas passar para os filhos e do acesso à informação por parte dos adolescentes, que supera o de seus responsáveis. Nesse ponto nos deparamos com a relevância do acesso à internet e mídias digitais como uma interferência nas relações de poder dentro da família.

$A$ acesso à internet permite que crianças e adolescentes entrem em contato com todo tipo de conteúdo, sem que seja possível um controle parental, dessa forma, os pais perdem parte do poder sobre quais influências o filho receberá (SALLES, 2005; JUTKOSKI,2009). Com o acesso à imensa variedade de informação que pode ser encontrada online, o adolescente expande suas possiblidades na construção de sua identidade, valores e referenciais, não se limitando àqueles que são preconizados por sua família. Além isso não é raro que o adolescente possua mais domínio sobre como utilizar os recursos virtuais que seus pais e/ou responsáveis, situação essa que traz uma inversão nas relações de poder, ao tornar o adolescente, e não o adulto, o detentor do conhecimento (SALLES, 2005; JUTKOSKI,2009).

A possibilidade de se relacionar virtualmente é outro elemento influenciador na formação da personalidade dos adolescentes. De acordo com Jutkoski (2009), a adolescência tem como característica a procura de uma identidade e sua inserção em um grupo social que, além da que a família, também passa a servir de referência para sua formação identitária.

Dessa forma, um aspecto fundamental na relação entre os adolescentes e a família é a incorporação de "outros", estranhos ao meio familiar, nesta relação. Na adolescência o grupo de amigos vai apresentar um papel essencial para o adolescente na busca de um sentido para a sua existência pessoal. O processo de o adolescente tentar se encontrar na sociedade vai influenciar diretamente em sua relação com as pessoas e consequentemente em sua relação com a família. (JUTKOSKI, 2009, p.43, 44)

A utilização da internet como recurso de interação e estabelecimento de relacionamento, amplia o leque de grupos e pessoas com quem o adolescente pode se relacionar e, consequentemente, exposição aos tipos de influências que contribuirão na formação da sua identidade. Além disso, o virtual permite que essas relações se tornem mais intensas, na medida em que estas podem ser acessadas a qualquer momento e em qualquer lugar, o que é ainda mais acentuado quando os 
jovens possuem o smartphone, o que amplia sua privacidade (NICOLACl, 2004b). Dessa forma, observa-se que que o controle e influência dos pais no processo de socialização e formação da identidade de seus filhos adolescentes compete com forças externas cada vez mais poderosas.

\section{Metodologia}

A fim de examinar o fenômeno, o estudo utilizou uma abordagem qualitativa. Para tal, foram selecionadas três famílias através de uma amostra por conveniência, "quando o pesquisador escolhe ou é forçado a escolher, por questões práticas, os sujeitos ou elementos que Ihe são disponíveis"(SANTO,1992, p.134), sendo que a única exigência era que tivessem adolescentes, com acesso à internet em suas casas, independente dos meios para tal. Entende-se aqui como "adolescente", indivíduos com idade cronológica entre 10 e 19 anos, de acordo com as definições da OMS (EISENSTEIN, 2005).

Das famílias selecionadas, duas pertenciam à classe econômica $\mathrm{C} 1$ e uma a classe B2, de acordo com o Critério Brasil (CCEB, 2016), produzido pela ABEP (Associação Brasileira de Empresas de Pesquisa). Todas possuíam apenas adolescentes do sexo feminino em suas casas, com idades entre 11 e 15 anos, o que dá à essa pesquisa um recorte de gênero inicialmente não planejado.

Os dados foram coletados no período de novembro e dezembro de 2017 mediante a aceitação dos pais e dos adolescentes e a autorização dos pais e responsáveis por meio do Termo de Consentimento Livre e Esclarecido. Para a coleta foram realizadas entrevistas semiestruturadas individuais, com o pai e a mãe de cada família, com o objetivo de identificar suas representações sobre o uso da internet por parte dos seus filhos e as possíveis estratégias utilizadas para controlar esse uso.

Em paralelo, também foram realizadas entrevistas semiestruturadas individuais com os adolescentes, tendo como objetivo identificar os principais usos da internet por parte dos mesmos, bem como o tempo de utilização da internet e suas representações frente as regras dos pais sobre esse uso e as estratégias que utilizam para fugir do controle dos mesmos. As "representações" são aqui entendidas como "sistemas de interpretação, que regem nossa relação com o mundo e com os outros, orientando e organizando as condutas e as comunicações sociais" (JODELET, 2001, p.5), sendo de suma importância conhecer, então, o que os participantes da pesquisa representam sobre temas como uso da internet e controle parental.

Como estratégia de triangulação, também foram realizadas observações participantes nas residências das famílias, para examinar a dinâmica das relações de poder envolvidas no uso cotidiano da internet, com destaque ao surgimento de possíveis focos de tensão. Faz-se importante salientar que, apesar da não interação do pesquisador com os indivíduos durante os episódios de observação, compreendese que a presença de um observador tem, sim, o poder de interferir no ambiente, ainda mais em situações geralmente tão íntimas como o convívio familiar no ambiente doméstico, razão pela qual classificamos a observação como participante.

Essas observações foram realizadas nas residências de cada família, sendo uma em cada turno do dia durante um final de semana e em dois turnos do dia durante uma semana. No total, foram cinco episódios de observação, alguns destes em dias alternados e alguns no mesmo dia, em turnos diferentes, a depender da conveniência. Cada observação teve a duração média de uma hora.

Após a coleta, os dados foram analisados a fim de encontrar indicadores das relações de poder expressos no uso da internet dentro de casa, bem como padrões de comportamento que demonstrassem a influência desta nessas relações. Com o 
intuito de se encontrar padrões, as entrevistas foram analisadas verticalmente, verificando as respostas individuais de cada participante às perguntas e horizontalmente, examinando as respostas dos diferentes participantes à uma mesma pergunta.

As observações também foram analisadas de forma a se buscar possíveis divergências ou confirmações do que foi dito nas entrevistas, assim como a presença de conflitos e comportamentos relevantes relacionados ao uso da internet por parte dos pais e filhos no ambiente doméstico. Ao fim da pesquisa, os sujeitos foram informados sobre os resultados do trabalho.

\section{Resultados}

Para a apresentação dos resultados foram adotados codinomes, sendo cada família identificada por números (1 a 3) e seus membros por um nome fictício.

Tabela 1 - Codificação dos membros das famílias

\begin{tabular}{l|l|l|l}
\hline Membros & Família 1 & Família 2 & Família 3 \\
\hline Pai & José & Joaquim & João \\
\hline Mãe & Lúcia & Ana & Maria \\
\hline Filhos & Mariana, Juliana & Priscila & Gabriela, Manuela \\
\hline
\end{tabular}

Fonte: Os autores (2020)

Dos seis pais entrevistados, quatro declararam se raramente comunicar com as filhas utilizando a internet. Um deles argumentou que a comunicação com as filhas via internet dependia das mesmas possuírem pacote de dados móvel, o que nem sempre era possível: "Raramente. As vezes quando eles estão na rua, mas nem sempre eles têm internet no celular" (Lúcia). Assim, a comunicação via internet se dava predominantemente através de mensagens de texto, seja pelo aplicativo WhatsApp ou pelo Facebook. Apenas dois dos pais entrevistados, João e Ana, declararam se comunicar via internet com as filhas.

Quanto as filhas, pode-se dividi-las entre aquelas que responderam não se comunicar com os pais via internet e aquelas que responderam se comunicar, mas apenas em casos de necessidade: "Não, só quando é bem preciso." (Juliana); "Mas se eu tiver dentro de casa e eles tiverem fora e eu precisar falar, aí às vezes eu tipo, mando mensagem pro meu pai, pelo WhatsApp ou ligo." (Mariana).

Não houve relato de comunicação com os pais via internet ocorrer de forma descontraída ou frequente. Percebeu-se a existência de um protocolo específico para a ocorrência dessa comunicação, que é a sua necessidade. As filhas entrevistadas disseram passar bastante tempo conectadas à internet, o que demostra que reconhecem como excessiva a quantidade de tempo online, embora as respostas variem sobre o total de horas gastas. Foi observado que essa noção do que seria muito tempo variou entre as adolescentes. Juliana disse passar mais de 15 horas conectada à internet, só deixando-a de lado quando está "com a mão debaixo d'água" (Juliana). Tal fato foi confirmado durante as observações, quando observou-se o uso intenso da internet por parte de Juliana. Por outro lado, Manuela respondeu que não sabia ao certo quanto tempo passava na internet, mas que achava que devia ser muito, "umas três horas" (Manuela).

De modo geral, o uso intenso da internet por parte de quase todas as adolescentes pôde ser confirmado durante as observações, nas quais notou-se que a 
maioria usa o celular para acessar a internet de forma ativa, até mesmo quando o aparelho está carregando ou sendo usado em chamadas telefônicas. As poucas pausas percebidas no uso da internet pelas adolescentes ocorreram quando estas assistiam algum filme ou quando conversavam com amigos ou familiares. Manuela foi a filha que demonstrou fazer menos uso da internet, tendo as maiores pausas.

As principais atividades virtuais relatadas pelas adolescentes foram o uso de redes sociais como: Facebook, WhatsApp, Instagram e YouTube, além de jogos. Algumas também relataram usar a internet para baixar músicas e jogos. Embora variasse o tempo de uso, o período noturno foi o mais utilizado, indo das nove horas da noite até as três da manhã.

Apesar de todos reclamarem, nenhum dos pais entrevistados "demonizou" o uso da internet pelas suas filhas. Eles reconheceram que a internet possui pontos positivos e negativos. Entre os pontos positivos citados estão a possibilidade de estudar e a aprender com a ajuda da internet e a facilidade de comunicação: "[...] porque eu acho que a internet ela tem muito ponto positivo, ela pode ajudar, inclusive nos estudos [...]." (José); "Positivo pelo fato de você... é... Aprender, é, sobre várias coisas. Sobre pesquisa, pesquisar coisas que você sente dúvida [...]." (Maria); "Bom, por um lado, eu acho bom, assim, pra gente, sabe, conversar algum assunto que a gente tá querendo conversar, a vez tá na escola alguma coisa assim, pra resolver, eu acho bom." (Ana).

Entre os pontos negativos citados, o que mais gerou reclamações ao longo das entrevistas foi o excesso de tempo dispendido pelas filhas na internet, o que, na visão dos pais, pode causar prejuízo em diversos aspectos da vida das adolescentes, tais como: privação de sono, falta de socialização, execução de tarefas domésticas e até a vivência da própria juventude: "Atrapalha na hora de dormir acordar cedo pra ir pro colégio, já interfere na educação do colégio, interfere nas obrigações de casa, que... que eles deixam de fazer porque ficam usando muito a internet." (José); "Eu peço pra ela parar porque ficar demais assim também prejudica, né. E ela às vezes nem estuda porque... pra tá no celular. Aí eu já acho fora do normal." (Ana).

Eu acho que rouba um pouquinho, né. Da... a juventude deles porque passar muito tempo na internet, né. Eu acho que... tem muitas coisas pra poder você enterter, interagir mais do que a internet, né. Porque eu acredito assim, que roubou muito a infância, a adolescência, a internet de modo geral, principalmente na vida dos meus filhos porque eles vivem na internet. (Lúcia)

Alguns pais falaram vaga e imprecisamente sobre possíveis pontos negativos sobre o uso da internet: "[...]eu penso que às vezes é bom, mas a gente tem um receio de às vezes prejudicar. Mas a gente tenta controlar da melhor forma possível." (João); "[...] e acho ruim pelo fato de você... às vezes, ter a oportunidade de pesquisar algo bom e entrar ne um lado negativo." (Maria); " [...] a internet ela tanto ajuda... pessoa não souber usar ela pode se contaminar com muita coisa, né.” (José).

A maioria dos pais relatou não estabelecer regras rígidas ou fixas na utilização da internet pelas filhas. E mesmo para os que declararam estabelecer regras, percebeu-se que o que ocorre predominantemente é a intervenção apenas quando percebem que as filhas estão utilizando a internet excessivamente ou em comportamentos considerados reprováveis. Maria foi a única que falou sobre uma regra claramente estabelecida: "Às vezes, sim. Às vezes é difícil pra gente controlar, porque cê precisa tá ali... é igual eu falei, eu tô vendo que tá demais, tá tarde, vou lá 
e ó (gesto de tesoura com as mãos)." (Ana); "Estabeleço. Estabeleço regras, é.... Tipo... alguns determinados sites, pornográfico... às vezes quando eu vejo que tá demais na internet eu coloco senha pra eles (?) usar mesmo, ter acesso a hora que quer." (Maria).

Ó, regra, assim, a gente não tem regra. A gente quando observa que tá muito, o uso tá muito... um... longo período, a gente vai e.... e ó, já chega, parou, tá na hora de parar com a internet hoje. Pronto, aí a gente cessa a internet. A partir do momento que foi dado ...a, a, a voz pra parar aí eles param. (João)

Durante as observações, quase não foram percebidos conflitos originados pelo uso da internet, o que demonstra que o intenso uso observado pelas filhas ainda estava num nível aceitável pelos pais, onde não julgam ser necessário nenhuma intervenção.

Todos os pais, com exceção de João, disseram achar importante a existência de regras para o uso da internet em suas casas, mesmo que estas não sejam bem definidas no ambiente doméstico. Eles atribuem essa importância à necessidade de controlar o uso excessivo da internet e restringir o acesso à conteúdos duvidosos. Foi possível identificar uma estratégia de controle por parte de uma das mães, Lúcia. Ao invés de estabelecer regras fixas, esta apelou para valores morais e princípios como forma de controle do comportamento das filhas:

[...] por ser evangélica, eu deixo pela consciência de cada um, mas eu explico que o que eles estão vendo, o que eu não estou vendo é consequência do que eles vão pagar depois. [...] Eu falo pra eles assim, o que vocês não estão vendo, o que eu não estou vendo, Deus está vendo e a consequência mais cedo ou mais tarde, ela vem. (Lúcia)

Lúcia também demonstrou acreditar que a autodisciplina seria uma alternativa para evitar uma intervenção: "[...] internet tem limite e se vocês não impor essas regras com vocês mesmo, se vocês não estabelecer um tempo, eu vou tirar o celular de vocês e eu vou estabelecer esse tempo e vai ser quinze, vinte dias sem celular." (Lúcia)

João, um dos pais, relatou não ver necessidade de estabelecer regras pelo fato das filhas obedecerem, sem relutância, suas determinações sobre o uso da internet:

Dos meus filhos, por exemplo eu não acho assim tão necessário uma regra, porque... como eles... quando a gente determina certo horário, olha, pode terminar (?) e desligar (?), eles cumprem, então acho que eu não vejo necessário ter regras. Tipo, regra escrita, ah, começar e terminar tal hora. Porque muitas vezes varia muito de acordo o dia, às vezes num entra na internet aí entra só um pouquinho à noite, então num tem que ter regra específica de horário de entrar e horário de sair. A gente controla mais o tempo quando a gente tá, que geralmente tá todo mundo em casa e controla, mas regras específica a gente não tem. (João) 
Percebe-se aqui, de forma contundente, que regras rígidas são vistas como um último recurso, podendo até ser confundida com punição e devendo ser usada apenas quando necessário. As providências relatadas, frente à possíveis comportamentos indesejáveis das filhas na utilização da internet, foram: chamar a atenção verbalmente ("dar bronca" ou conversar), tomar o celular ou restringir o acesso ao uso da internet. Maria falou sobre colocar as filhas de castigo, mas não explicitou que tipo de castigo seria.

Ao serem indagados sobre o estabelecimento de regras concernentes ao uso da internet, duas das adolescentes entrevistadas, Juliana e Mariana, disseram que os pais não estabeleciam regras, embora uma delas tenha, mais tarde, se contradito. $\mathrm{Na}$ fala de Mariana, observa-se o mesmo comportamento de intervenção que os pais revelaram ter apenas em horas críticas: "Aí eles falam, fi... deixa o celular quieto, não mexa na internet, fica um pou... um tempo fora, mas, assim determinado... não." (Mariana).

Uma das filhas, Manuela, demonstrou certa confusão sobre essa questão ao responder que os pais estabeleciam regras sobre o uso da internet, mas que ela não estava ciente sobre tais regras. Priscila, uma das outras filhas que disse que os pais tinham regras, disse saber "mais ou menos" sobre elas. Entre os filhos que disseram que os pais possuem regras, Gabriela foi a única que estipulou uma regra clara e específica: "[...] de manhã a minha mãe não gosta que eu... que a gente usa, que aí gosta que a gente mais trabalha em casa." (Gabriela).

Essa regra foi confirmada durante as observações feitas na residência da família 3. Apesar da visível confusão de algumas adolescentes sobre a existência ou não de regras e quais seriam elas, todas, mesmo as que disseram que os pais não estabeleciam regras, declararam estar cientes dos comportamentos que os pais consideravam reprováveis. Assim como os pais fizeram usos de expressões amplas e vagas para falar sobre determinados pontos negativos da internet, algumas adolescentes também utilizaram expressões similares sobre quais seriam as condutas condenadas por seus pais. Percebe-se, que essas condutas estariam mais relacionadas ao conteúdo do que ao excesso de uso (do qual os pais tanto reclamaram): "Não ver coisas, assim, que eu num posso." (Priscila, grifo nosso).

Eles deixam eu ficar nas minhas redes sociais, eles deixam eu pesquisar, deixam eu jogar, por exemplo, mas não assim, ficar em coisas mais impróprias, sabe? É o que eles.... as regras deles é essa. (Mariana, grifo nosso)

Ao serem indagados sobre o que pensavam a respeito do controle e das tentativas de controle dos pais sobre as suas atividades na internet, todas as adolescentes, com exceção de Juliana, disseram achar "chato" e "errado". Juliana se mostrou indiferente a essa questão, alegando que por não passar muito tempo dentro de casa, estaria fora do controle dos pais. Gabriela levantou uma perspectiva diferente, reconhecendo esse comportamento parental como um sinônimo de cuidado, mas que ao mesmo tempo implicava na privacidade: "Bom, eu acho... certo. Acho às vezes certo. Tem que ficar sempre ligado que eu tô mexendo na internet e tal. Mas às vezes eu acho errado, porque... eles toma conta da nossa privacidade." (Gabriela). Sua irmã, Manuela, se referiu a esse controle como algo ruim, pelo fato de a atrapalhar quando está usando a internet para algo muito importante:

É... em certos momentos eu não gosto muito, porquê... dependendo do horário eu posso tá usando em alguma coisa muito importante e 
meus pais muitas vezes não gostam que eu fico usando muito... o celular e nem o computador. (Manuela)

Todos os pais, com exceção de Joaquim e João, admitiram já terem punido seus filhos retirando o acesso à internet, mesmo quando o comportamento alvo da punição não tinha nenhuma relação com o uso da mesma. Da mesma forma, os comportamentos virtuais considerados inadequados também se revelaram alvos de outras formas de punição, além da privação de acesso à rede. João, apesar de ser um dos pais que se mostrou mais flexível com a questão da internet, foi o único que fez menção ao castigo físico: "[...] se precisar umas palmadinhas." (João)

Na mesma família, Maria disse que sua forma de punição é cortar o lazer das filhas, impedindo-as de ir para algum lugar que queiram. José, curiosamente, disse que sua forma de punição é baseada no diálogo. Percebe-se que, assim como Lúcia, ele investe na consciência e moralidade como uma estratégia de controle, porém, com foco mais intenso não na prevenção, mas na punição de comportamentos considerados indesejados:

A outra forma de punição que eu __ com os filhos é o diálogo. Mas eu converso com eles e e.... assim... às vezes eles preferem até levar uma coça do que conversar comigo, né... Porque eu atinjo o psicológico deles. Às vezes eu pego eles na conversa, eu consigo tocar na mente deles, sabe, eles ficam chorando e se acabam em lágrimas pra lá e tal, se arrepende... (José)

Apenas uma, dentre as filhas, alegou bloquear os pais em aplicativos, sites ou redes sociais, justificando sua atitude pelo excesso de vigilância: "Porque às vezes quando eu saio fica mandando muito mensagem. É. Fica olhando assim, falando assim das minhas fotos e tal no facebook. É isso." (Priscila).

O fato das outras filhas não bloquearem os pais em aplicativos, sites e redes sociais é algo interessante visto que, com exceção de Joaquim, todos os pais usam pelo menos uma forma de observar as atividades online de suas filhas, tais como: observando suas postagens no Facebook, verificando o horário do último acesso no WhatsApp, vendo as fotos que foram postadas nas redes sociais, verificando quem são as pessoas que curtem e comentam as fotos e postagens das filhas em redes sociais, dentre outros mecanismos.

Foi possível perceber que os pais demonstram preocupação sobre com quem as filhas interagem online, principalmente se essa pessoa for do sexo oposto: "[...] então, eu pergunto: quem é esse menino que tá aqui comentando na sua foto e tal." (Lúcia); "Quando eles coloca alguma foto eu observo quem comentou, ás vezes eu abro até o perfil de quem comentou, principalmente se for sexo oposto pra saber quem é [...]" (Maria);"Num gosto que cê fica conversando com tudo quanto é menino, menino que você num conhece. Até então, seus colega, algum colega de sala, ainda vai. Mas pessoas que você não conhece, que você não tem muito conhecimento, não é bom." (Maria).

Apenas dois pais declararam desligar a wi-fi da casa ou desconectar os aparelhos disponíveis para impedir que as filhas acessassem a internet. Um deles ainda salientou que faz isso quando "tá demais". Em relação a tomar ou impedir (no caso do computador) que as filhas tenham acesso aos aparelhos para se conectar à internet, apenas dois pais disseram não adotar esse comportamento. João disse: "Eu proíbo elas de usar e elas param de usar. Não desligo, nem tomo o wi-fi. Nem tomo o celular, aliás. Nunca cheguei a fazer isso, não." (João). 
Nenhum dos pais mencionou utilizar programas específicos para impedir que as filhas acessem a internet ou determinados conteúdos dela. Maria, admite colocar senha no computador para impedir que as filhas acessem a internet a qualquer hora. Uma forma apontada como alternativa de conexão à internet, caso a wi-fi estivesse desligada, foi o uso de dados móveis, mencionada por Mariana. No entanto, pelo fato da internet móvel ser acessível por crédito colocado pelos pais no celular dos filhos, esta torna-se uma forma de subordinação ao controle parental. Gabriela e Manuela admitiram se conectar à internet nestas situações, roteando a internet pelo celular da mãe. Nas palavras de Manuela:

Minha mãe tem internet no próprio celular, aí eu rotio pra mim mesma. Eu uso o wi-fi da minha mãe, no celular dela. [No caso se desligarem a sua wi-fi...]. Eu vou lá e ligo o wi-fi dela e conecto no meu celular. [Mas ela sabe quando você faz isso ou você faz isso assim... na surdina?] Ás vezes não, mas aí eu faço escondido.

Embora ninguém reporte utilizar algum programa específico para rastrear as atividades online das adolescentes, todos os pais, com exceção de Joaquim, admitiram examinar os aparelhos que suas filhas usam para se conectar e os rastros que elas podem vir a deixar de suas atividades online. João e José foram dois pais que desenvolveram a estratégia de "pegar os filhos de surpresa" examinando seus aparelhos sem aviso prévio.

As filhas, por sua vez, declararam apagar, pelo menos algum tipo de rastro, de suas atividades online, como: mensagens, registro de uso de aplicativos, histórico do YouTube, etc. As razões pelas quais elas apagam o histórico de navegação são as mais diversas: seja porque não gostam que as pessoas fiquem pegando o seu celular (Manuela), seja para que elas próprias não vejam novamente (Juliana) ou para deixar o celular mais leve (Mariana).

Em relação as senhas nos aparelhos usados para acessar a internet, duas das adolescentes, Mariana e Manuela, disseram usar senha no celular, mas "só na tela de bloqueio". Gabriela foi a única que enfatizou o uso da senha como se isso fosse algo essencial. Nenhuma das meninas diz usar mecanismos como bloqueios de tela ou fones de ouvido no intuito de esconder suas atividades ao usarem a internet perto de seus pais. Elas admitem usar esses mecanismos, sim. No entanto, apenas porque querem e gostam (no caso do fone de ouvido) e não porque têm a intenção de esconder algo.

Da mesma forma, nenhuma delas mencionou esperar que seus pais se ausentem, durmam ou se distraiam para fazer uso da internet. Todas, com exceção de Gabriela, declararam se sentir confortáveis para usar a internet na presença de seus pais, pois não têm nada a esconder ou não fazem nada de errado. Essa despreocupação pôde ser confirmada nas observações, principalmente na família $1 \mathrm{e}$ 2 , onde se vê que as filhas não têm bloqueios e amarras quanto a utilizar a internet na presença dos pais. Gabriela, a única das adolescentes que disse que não se sentir confortável, justificou esse desconforto por achar que os pais "ficam de olho e que não gosta que eles fiquem sabendo das coisas que ela mexe, apesar de não fazer nada de errado" (Gabriela).

Todos os pais, com exceção de Joaquim, declaram questionar as filhas sobre o que eles fazem na internet. Porém, a abertura das filhas para falar espontaneamente com seus pais sobre suas atividades na internet é reduzida. Duas das filhas entrevistadas disseram não falar com os pais sobre suas atividades na internet e duas deram respostas que indicaram seletividade no que comentam: "Às vezes, sim, às 
vezes, não." (Gabriela); "Algumas sim." (Mariana). Apenas Priscila, respondeu com "Sim" sobre falar com sua mãe sobre suas atividades na internet, resposta confirmada pelas observações realizadas.

A maioria dos pais acreditavam conhecer boa parte das atividades de suas filhas na internet. Alguns inclusive, foram capazes de dizer quais eram essas atividades. Nas famílias 1 e 2, percebe-se que que os fatores que auxiliam nessa informação são: o fato das filhas usarem livremente a internet na presença dos pais o que pôde ser confirmado através das observações - e o próprio acesso que alguns pais têm aos aparelhos das filhas. Nessas famílias, esse aceso vai além daquele que se têm quando se examina ocasionalmente os aparelhos celulares dos filhos. Ana e José são pais que demonstraram ter um amplo acesso à vida virtual de suas filhas, sabendo com quem elas conversavam e chegando até mesmo a ter suas senhas do Facebook para excluir amizades consideradas impróprias: "O que acontece às vezes, eu pego e dou uma olhada, né.

Nas mensagens do Face, com quem que ela tá falando, o que que ela tá vendo. Isso aí eu já fiz, já." (Ana); "Eu tenho a senha do Face... Essas coisas assim eu faço questão de ter. Aí eu mesmo excluo certas amizades e se vier me perguntar eu falo logo ó, num quero amigo bandido." (José). O acesso de Ana ao celular da filha foi presenciado durante uma das observações, quando Priscila se ausentou da sala e deixou o celular no sofá, Ana examinou o aparelho da filha. Apesar desse acesso, os pais da Família 1, da qual José faz parte, em vários momentos se mostraram cientes do fato das filhas serem capazes de esconder suas atividades na internet $\mathrm{e}$ consideraram essa possibilidade como elemento para definir a condução de suas ações. Lúcia, inclusive, ressaltou o fato de que seus filhos sabem utilizar os recursos digitais melhor do que ela: "Mas eles são bem espertos, tira até aquela coisa que pode utilizar pra você não ver o tempo que passou na internet, no WhatsApp. Tem uma forma aí que você usa, né?" (Lúcia); "É como eu tô te falando, tem muitas coisas que eles podem fazer escondido e depois apagar. Então quando eu for pegar... pegar pra olhar não tem como acompanhar, mas o que eu posso, o que eu consigo tudo eu acompanho, eu acompanho sim." (José).

Todas as filhas admitiram usar a internet para fazer e falar sobre coisas que não se sentem à vontade para falar em casa. Ou seja, a internet é um espaço onde elas se sentem mais à vontade de conversar sobre temas sensíveis.

\section{Discussão}

As famílias estudadas têm estilos diferenciados de lidar com o acesso à internet de seus filhos, percebendo-se a coexistência de aspectos modernos e pós-modernos nas relações de poder entre pais e filhos, aspectos esses que aparecem tanto no discurso, quanto na prática, revelando o contexto no qual a família está inserida (DUARTE, 2001). As famílias estudadas neste texto podem reproduzir algumas características da sociedade pós-moderna que coexistem com características da família tradicional.

O uso do diálogo talvez seja um dos melhores indicadores de como esses aspectos do moderno e pós-moderno coexistem nas relações entre pais e filhos. Por um lado, ele é usado como forma de orientação da conduta dos filhos, sendo preferido ao invés da punições e regras rígidas. Os pais conduzem a conduta de seus filhos através de conversas, o que acaba configurando um caráter de igualdade e flexibilidade às relações, elemento peculiar da pós-modernidade e com traços típicos do que é considerado um modelo de bom relacionamento na pós-modernidade, que segundo Giddens (2007, p. 71), é aquele que é similar a democracia pública, isento 
da violência, coerção, e uso arbitrário do poder, onde as partes envolvidas podem manifestar suas vontades e opiniões.

Por outro lado, ainda é possível perceber certa rigidez nos papéis, pois o diálogo quase sempre é utilizado apenas nos aspectos considerados necessários: orientação e correção dos filhos. Os diálogos domésticos observados, quando não versaram sobre assuntos "necessários", (como por exemplo, execução de tarefas domésticas) eram pontuais e esparsos. A comunicação via internet reflete essa rigidez, visto que era realizada quase sempre em função de necessidades, nunca de forma amigável, descontraída ou espontânea.

Uma característica que se sobressai nas relações entre os pais e filhos das famílias estudadas, é a fluidez no estabelecimento de regras e limites, principalmente em relação à intensidade do uso da internet. Dentre os pais entrevistados, alguns dizem não estabelecer regras, intervindo apenas quando considerarem necessário. Como resultado, os filhos não possuem uma noção clara de qual deva ser o seu comportamento com relação ao tempo de uso da Internet. É possível concluir através das entrevistas e observações feitas, que o uso da internet considerado como normal é intenso e quase ininterrupto. A elasticidade sobre o limite do tempo de uso da internet é caracterizada pela indefinição e inexistência de modelos rígidos, o que remonta à fluidez característica da pós-modernidade (NICOLACI, 2004a).

Essa fluidez e indefinição de contornos também se mostra presente na visível confusão sobre quais seriam os limites e castigos aplicáveis. É possível notar que as regras rígidas e limites bem definidos sobre a intensidade do uso da internet, são vistos como importantes pela maioria dos pais. Mas, seu estabelecimento, além ser feito só em momentos críticos, confunde-se com punição, sendo, em alguns casos, usado explicitamente para punir. Estabelece-se aqui uma indefinição sobre o quais seriam os limites e o que seria o castigo adequado por ultrapassá-lo. Isso se reflete na dicotomia da atitude dos pais em estabelecer, ou não, regras ou limites para o uso da internet, ou mesmo em cortar o seu uso como forma de punição.

No entanto, se há uma indefinição em relação ao limite de tempo e intensidade de uso da internet, o mesmo não se pode dizer sobre o conteúdo acessado. Isso pode ser percebido através das falas de algumas filhas e pais entrevistados: "Eles deixam eu ficar nas minhas redes sociais, eles deixam eu pesquisar, deixam eu jogar, por exemplo, mas não assim, ficar em coisas mais impróprias, sabe? É o que eles.... as regras deles é essa." (Mariana, grifo nosso). "Não ver coisas, assim, que eu num posso." (Priscila, grifo nosso). "Estabeleço. Estabeleço regras, é.... Tipo... alguns determinados sites, pornográfico... às vezes quando eu vejo que tá demais na internet eu coloco senha pra eles (?) usar mesmo, ter acesso a hora que quer." (Maria, grifo nosso).

Observa-se na fala de Maria, como o tratamento é diferente com relação aos limites de tempo/intensidade de uso e o acesso à determinados conteúdos. Enquanto a mesma cita sites pornográficos, dando a entender que é regra não acessá-los, a sua intervenção em relação ao uso excessivo das filhas só ocorre quando este já está acontecendo ou quando ela vê que houveram excessos. Aqui pode-se perceber que os limites de uso observados ganham características híbridas. Se os limites de tempo para o uso da internet são elásticos, os limites relacionados ao acesso de conteúdo são bem estabelecidos. As filhas sabem exatamente o que devem ou não acessar, e os pais, ao contrário do que acontece com a questão do tempo de uso, impõe um limite bem definido. É interessante ressaltar que todas as filhas dizem estar cientes do comportamento que seus pais desejam que elas tenham na utilização da internet, apesar de não apontarem a existência de regras. 
No ambiente doméstico foi possível perceber que as relações de poder são profundamente afetadas pela questão do domínio do uso da tecnologia digital. Neste caso, ocorre uma pulverização do poder, onde quem tem mais domínio está em vantagem e é capaz de burlar as estratégias de controle ou fuga do controle do outro. Dessa forma, se as filhas conseguem manusear melhor a internet e os aparelhos digitais do que seus pais, elas também têm mais condições de burlar o controle parental ou até mesmo, impedir o estabelecimento desse controle. Isso fica evidente na família 3, quando as meninas dizem rotear a wi-fi do celular da mãe para continuar acessando a internet. Na família 2, é gritante a conduta de Joaquim com relação ao controle do uso da internet de sua filha. Por não ter nenhum conhecimento sobre as tecnologia e recursos digitais, não tem como acompanhar ou intervir nas atividades que sua filha realiza nesse ambiente.

A inversão das relações de poder possibilitada pelo domínio da tecnologia não se revela apenas na questão do controle parental mas também em outros momentos da vida doméstica. Um exemplo é quando Lúcia, em um dado momento das observações, necessita que sua filha faça para ela uma pesquisa na internet, pois ela não sabe como fazê-lo. Há aqui uma espécie de inversão de poder, onde o pai é obrigado a recorrer ao filho, pois ele é o detentor do conhecimento (SALLES, 2005; JUTKOSKI, 2009). Assim observa-se a tendência pós-moderna de inversão das relações de poder devido ao maior conhecimento que os filhos possuem do manuseio da tecnologia digital (SALLES, 2005).

Por outro lado, os pais que têm algum conhecimento sobre tecnologias digitais encontram, nesse contexto, formas de exercer seu poder sobre os filhos, controlando, ainda que parcialmente, sua liberdade ou acompanhando suas atividades. Os pais com acesso às redes sociais das filhas, são um exemplo de como essa influência se dá: eles podem saber, ainda que de forma parcial, com quem as filhas estão interagindo virtualmente e tentar interferir nesses relacionamentos. É interessante salientar que, por causa da internet, existe uma forte preocupação de que suas filhas possam se relacionar com pessoas consideradas inadequadas. Assim, os pais encontram uma forma de ampliar sua interferência sobre a socialização online das filhas. O poder e o controle nas relações pai-filho, por se basear no domínio da tecnologia ao invés de na autoridade torna-se oscilante. O poder parental não está excluído, mas torna-se parcialmente condicionado a capacidade de manuseio dos recursos digitais e à superação das estratégias de fuga desse controle.

O uso do celular como principal forma de acesso à internet, mais utilizado pelos adolescentes dessa pesquisa do que o computador, é outro ponto que influencia nas relações de poder dentro de casa, pois este amplia as chances de uma vida privada, de contatar pessoas quando se deseja e ainda, de facilitar que os rastros das atividades sejam apagados (NICOLACl, 2004b). Nas famílias observadas, todas as filhas possuem um celular e todas sabem como colocar senhas no aparelho ou apagar o histórico de navegação e dessa forma, escondê-las de seus pais.

Estabelece-se, assim mais uma característica pós-moderna nas relações de poder entre pais e filhos: a incerteza. Apesar de alguns dos pais entrevistados terem acesso até mesmo à senha do Facebook de suas filhas e examinarem seus celulares e conversas, não impede que as filhas, por terem um celular pessoal e por saberem como apagar os seus rastros, burlem o controle dos pais. Assim, a relação pai-filho, baseada na confiança, torna-se não uma escolha, mas a única opção. O domínio da tecnologia e dos recursos digitais, aliado à posse de um celular pessoal dá aos filhos autonomia para fugir do controle dos pais. 
A família 1 é uma das famílias onde existe essa consciência e percebe-se a característica peculiar e até mesmo contraditória de "confiança" mencionada pelos pais, mas atrelada a vigilância, demonstrando aspectos diferenciados das relações pós-modernas. Se por um lado os pais informam ter confiança nos filhos e suas tentativas de controlá-los se dão através de diálogo e não da imposição de regras rígidas, por outro lado, há uma intensa vigilância, para garantir que essa confiança não seja quebrada, já que os filhos têm como burlá-la. Dessa forma, é uma "confiança vigilante", com características imprecisas: a confiança nunca é plena e a vigilância nunca é completamente eficaz.

Nesse sentido, torna-se importante levantar a questão da privacidade apontada por José e Gabriela. Nas falas, percebe-se a ideia de que a adolescente possui o direito à privacidade. José, apesar de chegar a falar sobre privacidade das filhas, reconhecendo sua atitude como invasiva, se sente no direito de invadir. O reconhecimento de que os filhos podem ter privacidade é pós-moderno, mas a afirmação de que pode invadir essa privacidade por ter o direito de corrigir e monitorar é pautada em valores da família tradicional, onde a autoridade dos pais sobre os filhos é incontestável (PRATTA e SANTOS, 2007).

Percebeu-se também, nas famílias estudadas, que a existência de novos determinantes das relações de poder possibilitou o surgimento de novas estratégias de controle. Lúcia e José são um exemplo disso, ao apelarem para a moralidade das filhas como forma de controlá-las. Se por um lado, ambos usam princípios de conduta bem definidos, por outro lado, ao apelarem para a consciência de suas filhas, Ihes dão autonomia para aceitar ou não esses princípios e os incorporarem ou não na sua conduta. Há um apelo a aceitação pessoal de valores por parte das filhas, que pode vir ou não a acontecer.

Essa autonomia é ainda mais evidenciada na família 1, quando Lúcia, dá a entender que antes que seja necessária sua intervenção, dá às filhas uma chance de se autodisciplinarem. Assim observa-se que, ao contrário do que acontecia na família tradicional, alguns filhos adquirem autonomia, ainda que não total, de definir seus próprios limites, exemplificando a horizontalização nas relações pós-modernas.

Outra forma de controle, criada pelas novas condições de poder no ambiente doméstico, é a verificação exame surpresa dos celulares. José e João reportaram que pegam as filhas de surpresa, usando o celular, evitando assim que elas tenham tempo de apagar o rastro de suas atividades virtuais.

Baseado na amostra deste estudo, pode-se inferir que os pais não perderam seu poder, pois ainda há formas de controle e punição que os filhos não conseguem burlar ou das quais não conseguem fugir, como por exemplo a privação de acesso ao celular e as punições como: cortar o lazer temporariamente e castigar fisicamente. Mas, na maior parte do tempo, o controle dos filhos ocorre através do diálogo. No entanto, há também pais que apelam para sua autoridade como forma de controle, como é o caso de João, confirmando que características modernas e pós-modernas coexistem nas relações familiares atuais.

\section{Conclusão}

A presente pesquisa permitiu que fossem identificados nas famílias estudadas um interessante mosaico, onde influencias tradicionais e pós-modernas coexistem, afetando de forma diferenciada as relações de poder. Pais e filhos apresentam condutas e discursos que demonstram essa dualidade de hora apelar para a rigidez e regras que caracterizam as relações de poder na família tradicional, hora optar pelo diálogo como forma de solucionar conflitos. Há uma incorporação de valores e características pós-modernas, mas sem o abandono de certos preceitos da família 
nos moldes tradicionais. Dessa forma, percebe-se uma flexibilização das relações no ambiente familiar, mas, ao mesmo tempo, a busca pela manutenção da função dessas relações na vida dos pais e filhos.

Pode-se perceber que o uso intenso da internet no ambiente doméstico, comum na vida das famílias estudadas e característico da sociedade atual, traz para as relações de poder novos determinantes, que demonstram em parte como as mudanças características da contemporaneidade afetam a família. No entanto, apesar de trazer um importante viés para a análise das relações de poder no ambiente doméstico, compreende-se que 0 uso da internet não reflete plenamente a complexidade dessas relações num contexto pós-moderno, tanto pela multiplicidade de modelos familiares característicos da contemporaneidade, quanto pelos vários aspectos que atravessam a vivência familiar atualmente.

Nesse sentido, é importante assinalar a importância da realização de pesquisas futuras com famílias de configurações mais diversas e focar em diferentes aspectos, além do uso da internet, para ser possível haver um entendimento mais completo das relações de poder entre pais e filhos na contemporaneidade.

\section{REFERÊNCIAS}

BARRETO, Maria José; RABELO, Aline Andrade; A Família e o Papel desafiador dos pais de adolescentes na contemporaneidade. Pensando Famílias, 19(2), p. 34-42, dez. 2015. Disponível em: <http://pepsic.bvsalud.org/pdf/penf/José 9n2/José 9n2a04.pdf.> Acesso em: 23 fev. 2019.

BERGER, Peter L. e LUCKMANN, Thommas. A construção social da realidade: Tratado de Sociologia do Conhecimento. Petrópolis: Vozes. 2004.

CCEB 2016. Disponível em: <http://www.abep.org/criterio-brasil> Acesso em 23 fev.2021.

CETIC.BR. Apresentação dos principais resultados TIC Kids Online Brasil 2015. São Paulo. 2016. Disponível em: <http://cetic.br/media/analises/tic kids 2015 coletiva de imprensa.pdf.> Acesso em: 03 jan. 2019.

DUARTE, Alda Cristina. As transformações nas relações de poder das famílias. Revista Brasileira de Terapia Familiar, 3(1), dez., 2011.

EISENSTEIN, Evelyn Adolescência: definições, conceitos e critérios. Adolescência \& Saúde, Rio de Janeiro, v. 2, n. 2, p. 6-7, abr./jun. 2005. Disponível em: $<$ http://www.adolescenciaesaude.com/detalhe artigo.asp?id=167>. Acesso em: 26 fev. 2021.

GIDDENS, Anthony. Mundo em descontrole: o que a globalização está fazendo de nós. Rio de Janeiro: Record, 2007.

GIDDENS, Anthony, SUTTON, Philip W. Conceitos Essenciais da Sociologia. São Paulo: Editora Unesp Digital, 2017.

HINTZ, Helena Centeno. Novos tempos, novas famílias? Da modernidade à pósmodernidade. Pensando Famílias, 3, p. 8 - 19, 2001. Disponível em: $<$ http://www.susepe.rs.gov.br/upload/1363010551 hintz novos tempos, novas fam \%JOÃO \%ADlias - complementar 8 abril.pdf.> Acesso em 12 jun. 2019.

JODELET, Denise. Representações sociais: um domínio em expansão. In As representações sociais, v. 17, p. 44, 2001. Disponível em: $<$ https://www.researchgate.net/profile/Denise-Jodelet-

/publication/324979211_Representacoes_sociais_Um_dominio_em_expansao/links/ 
5c4897c3a6fdccd6b5c2eab1/Representacoes-sociais-Um-dominio-emexpansao.pdf> Acesso em 24 fev. 2021.

JUTKOSKI, Marina. Relações de autoridade no âmbito da família de adolescentes: a fala dos alunos; Rio Claro: [s.n.], 2009. Disponível em: $<$ https://repositorio.unesp.br/bitstream/handle/11449/119494/jutkoski m tcc rcla.pdf ?sequence $=1$. $>$ Acesso em: 23 fev. 2019.

NICOLACI-DA-COSTA, Ana Maria. A Passagem interna da Modernidade para a Pósmodernidade. Psicologia, Ciência e Profissão, 24 (1), p. 82-93, 2004(a). Disponível em: <http://pepsic.bvsalud.org/pdf/pcp/v24n1/v24n1a10.pdf.> Acesso em: 23 fev. 2019.

Impactos psicológicos do uso de celulares: uma pesquisa exploratória com jovens brasileiros. Psicologia: Teoria e pesquisa, n.2, vol. 20, p. 165-174, mai-ago. 2004(b). Disponível em: $<$ http://www.scielo.br/pdf/ptp/v20n2/a09v20n2.pdf >. Acesso em: 23 fev. 2019.

. Celulares: a emergência de um novo tipo de controle materno.

Psicologia e Sociedade, 18 (3), p. 88-96, set/dez. 2006. Disponível em: <http://www.scielo.br/pdf/psoc/José 8n3/a13José 8n3.pdf.> Acesso em: 21 jul. 2019. OLIVEIRA, Lucélia Gabriel de. Pós-modernidade e adolescência: uma reflexão acerca das relações do adolescente sob o enfoque da psicologia corporal. Curitiba. 2010.Disponível em: <http://www.centroreichiano.com.br/artigos/Monografias/OLIVEIRA,\%20Lucelia\%20 Gabriel.pdf.> Acesso em 25 jun. 2019.

PRATTA, Elisângela M. M. e SANTOS, Manoel A. Família e Adolescência: a influência do contexto familiar no desenvolvimento psicológico de seus membros. Psicologia em Estudo, Maringá, n. 2, v. 12, p. 247-256, maio/ago. 2007. Disponível em: $<$ http://www.scielo.br/pdf/pe/José 2n2/José 2n2a05.> Acesso em 26 jun. 2019.

SALLES, Leila Maria Ferreira. Infância e adolescência na sociedade contemporânea: alguns apontamentos. Estudos de psicologia, Campinas, 22(1), p. 33-41, jan-mar. 2005. Disponível em: <http://www.scielo.br/pdf/estpsi/v22n1/v22n1a04.pdf.> Acesso em: 23 fev. 2019.

SANTO, Alexandre do Espírito. Delineamento de metodologia científica. Edições Loyola: São Paulo, 1992.

SCHOEN-FERREIRA, T. H; AZNAR-FARIAS, M; SILVARES, E. F. M; Adolescência através dos séculos. Psicologia: teoria e pesquisa, n. 2, vol. 26, p. 227- 234, abr/jun. 2010. Disponível em:<http://www.scielo.br/pdf/ptp/v26n2/a04v26n2.pdf.> Acesso em: 23 fev. 2019.

SOUZA, Ronald Pagnoncelli de. 0 adolescente do terceiro milênio. Porto Alegre: Mercado Aberto, 1999.

TORRES, Juliana B. e YACOUB, Giselle P. As relações familiares na contemporaneidade: conflitos e soluções. Apresentada no CONGRESSO INTERNACIONAL INTERDISCIPLINAR EM SOCIAIS E HUMANIDADES, Niterói RJ: ANINTER-SH/ PPGSD-UFF, 03 a 06 de Setembro de 2012, ISSN 2316-266X.

VAITSMAN, Jeni. Flexíveis e plurais: identidade e casamento em circunstâncias pósmodernas. Rio de Janeiro: Rocco, 1994. 